\section{Looking after the staff who care for patients: an essential investment for good quality care}

\author{
Fiona Moss
}

Evidence from many sources relates the quality of team work and team functioning to the quality of care. In short, being cared for by teams that function well, rather than those that do not, improves the quality of care and reduces the risk of both complications and death. If team working were a 'drug' it would be prescribed prophylactically to all patients on entry to any healthcare system. The characteristics of both good and poorly functioning teams have been defined. We know what is needed, but the process of changing teams' behaviours or developing those that function well seems difficult and takes even longer than introducing an effective intervention into everyday practice. A recently published report provides interesting details about the characteristics of the working environments and cultures in those organisations found to deliver better and safer care than average and suggests that good staff engagement is an important distinguishing feature.

Healthcare is complex and team working is therefore not straightforward. Patients with a single condition may depend on several teams for their caresometimes all at the same time. Take, for example, someone being diagnosed with lung cancer. Care starts with their primary care team followed, perhaps, by referral to a respiratory team and then onto a surgical or oncology team. But within each of those stages there will be others involved this person's care: the phlebotomy team; the endoscopy team; the pathology team. And, within each of the clinical teams, there may be defined subteams including nursing teams and medical firms.

Complexity cannot be used as an excuse for tolerating poor team structure or performance. But the barriers are formidable. In this issue, Weller et al ${ }^{1}$ categorise the barriers to effective team functioning in healthcare as educational, psychological and organisational. Separated education for clinical

Correspondence to Dr Fiona Moss, Editor in Chief, Postgraduate Medical Journal, BMJ, BMA House,

Tavistock Square, London WC1H 9JR, UK professionals, an inherently hierarchical system within healthcare, and different approaches to the organisation of different members of teams and geographical separation within teams, are just some of the factors that get in the way of developing well functioning teams throughout healthcare. Despite all these difficulties, some teams flourish, work well together and as a consequence deliver significantly better and safer care than those teams that do not.

Understanding the differences between good, merely ordinary and poorly functioning teams should be a priority for all in healthcare because it matters so much for patients. The report of a 2-year research programme assessed the extent to which NHS organisations in England have cultures that foster good quality care. Through the analysis of data from a number of sources, it evaluated examples of NHS organisations able to deliver good patient outcomes or 'bright spots' and contrasted these with their obverse, 'dark spots'. Inconsistency, being task- rather than patient-focused, poor handovers and problems at the many interfaces between adjacent teams were just some of the characteristics of 'dark spots'. Not surprisingly, the presence of well structured teams-those whose members reported having clear objectives, were required to work independently but met regularlywere found to be associated positively with a range of patient outcomes. ${ }^{2}$

Staff engagement-a combination of motivation, ability to contribute and advocacy for the organisation-was also found to be a key factor linked to outcome. Better engagement was associated with lower hospital standardised mortality. $^{2}$ Perhaps, trying to improve staff engagement would be a helpful way to start the process of improving team function. Good engagement happens where 'staff feel valued and respected and supported and where relationships between teams, and between departments are good'. 3 Staff who had well structured appraisals expressed better engagement that those who did not. But, the report suggests, having no appraisal at all may be better than suffering a poor quality one.

Much of the attention on the healthcare workforce is on the clinical workforce. 'Team' usually implies a clinical team and discussion about the importance of education and training focuses almost entirely on doctors and nurses. All clinical care requires organisational support and improvements in care require organisational change. For managers who have organisational responsibility and for those in HR, responsibility for all staff and their welfare at work, are going to be key if these basic human factors required for good staff engagement and well-structured functional teams are to be put back where they are missing.

Managers may be having as tough a time as anyone working in healthcare. A study of middle managers (for this study 'middle' meant any role below board level that included managerial responsibilities) in the NHS found that, although more than a third of NHS staff had managerial responsibilities, only one in four was a full time manager: the rest were described as 'hybrids' who juggled managerial responsibility with other work, usually clinical, and may not even have considered themselves to be managers. Work for some was described as 'extreme' and many of the problems they faced were 'wicked'. Many had had only limited training for these testing roles. ${ }^{3}$ Managers, whether full time or 'hybrid', need training and regular continual professional and personal development as much as their clinical colleagues.

Bridging the gap between what we know is needed and the realities of daily life for the 1.7 million people who work in the NHS in the UK is one of the objectives of a report just out from the Point of Care Foundation. ${ }^{5}$ It puts the case for making the support of staff a 'central driver' of quality improvement strategies. Staff engagement is not an optional extra, nor is it something that is solely the responsibility of those with a defined managerial responsibility or 'manager' somewhere in their title or job description. Looking after and looking out for colleagues should be part of everyone's role but it is a particular responsibility of senior staff-including senior clinicians. Line management is an important role: good line management is likely to lead to better employee engagement. All line managers should be skilled in supporting those they manage through a structured and useful and relevant appraisal. For this they will need training. Yet how many 
doctors regard themselves as line managers? How many doctors are skilled in appraisal? Fundamental HR skills should be part of the training package of all clinicians.

If staff wellbeing and staff engagement are a central responsibility of employing organisations, that responsibility should extend to making sure that all staff know about how to work well with othershowever complex the structures around them. Hospitals and other employing organisations should see that their responsibility as employers extends to junior doctors and residents, who must also be supported and engaged as employees even if their stay with the organisation is short and their status is that of 'trainee'. For doctors in training also contribute massively to the care of patients and are employees who deserve the care of a good employer. Being a good employee is so much more likely if people are working for a good employer.

Healthcare is often pressured and stressful-that is the nature of some aspects of clinical work. Additional stressors linked to working in situations that diminish engagement are detrimental to the health of employees and their patients. Without support, staff will disengage and possibly suffer burnout. If a healthcare organisation is to look after its patients properly, it needs well structured, well functioning teams that can work together to deliver high quality care. For that to happen all staff-from receptionist to senior consultant, from junior physiotherapist to the CEO_-must be respected, valued, listened to and be engaged. If this requires resources or training in how to manage people or how to be an effective line manager or how to appraise and set objectives, or stronger HR support, then just ask the finance director-after all, good staff engagement has also been found to be associated with good financial outcomes. $^{2}$

\section{Competing interests None.}

Provenance and peer review Commissioned; internally peer reviewed.

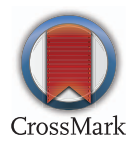

To cite Moss F. Postgrad Med J 2014;90:123-124.

Received 28 January 2014

Accepted 28 January 2014

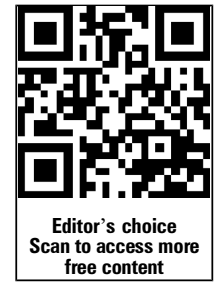

Postgrad Med J 2014;90:123-124.

doi:10.1136/postgradmedj-2014-132604

\section{REFERENCES}

1 Weller J, Boyd M, Cumin D. Teams, tribes and patient safety: overcoming barriers to effective teamwork in health care. Postgrad Med J 2014;90:149-54.

2 West M, Baker R, Dawson J, et al. Quality and Safety in the NHS: Evaluating Progress, Problems and Promise. Report; 2013. http://www.lums.lancs.ac.uk/ files/quality-safety-nhs-e.pdf

3 West M, Dawson J. Employee Engagement and NHS performance. Kings Fund, 2012. http://www. kingsfund.org.uk/sites/files/kf/employee-engagementnhs-performance-west-dawson-leadership-review2012paper.pdf

4 Buchanan DA, Denyer D, Jaina J, et al. How do they manage? A qualitative study of the realities of middle and front-line management work in health care. Health Serv Deliv Res 2013;1. http://www. journalslibrary.nihr.ac.uk/_data/.../FullReporthsdr01040.pdf

5 The Point of Care Foundation. Staff care. How to engage staff in the NHS and why it matters. 2014. http://www.pointofcarefoundation.org.uk/Downloads/ Staff-Report-2014.pdf 